\title{
Wind Turbine Control based on MRAS Methodology
}

\author{
A. G. Aissaoui ${ }^{1}$, A. Tahour ${ }^{1}$, I. Colak ${ }^{2}$, N. Essounbouli ${ }^{3}$, M. Abid ${ }^{1}$, \\ ${ }^{1}$ IRECOM Laboratory, Sidi Bel Abbes University, 22000, Algeria, \\ ${ }^{2}$ Engineering and Architecture Faculty of Nisantasi University, Istanbul, Turkey. \\ ${ }^{3}$ CReSTIC Laboratory, IUT de Troyes, 9 rue de Quebec BP 396, 10026, Troyes cedex-France \\ Received: January 10, 2021. Revised: March 22, 2021. Accepted: March 26, 2021. Published: April 1, 2021.
}

\begin{abstract}
The use of renewable energies has increased in these last decades. The wind energy attracts more attention of several research studies. The control of the power generated by the wind turbine is very complicated. It requires the application of new techniques of control. This paper presents an application of Model reference adaptive system (MRAS) in the control of wind turbine power. The structure of the proposed MRAS consists of Neuro fuzzy (NF) controller and an adaptive system based on sliding mode controller (SMC). The use of $\mathrm{NF}$ and SMC methodologies is very interest and it allows improving the performances of the system control. The $\mathrm{NF}$ has the advantages of expert knowledge of the fuzzy inference system and the learning capabilities of neural networks. The use of SMC gives more flexibility to the adaptive system. According to digital simulation results, the designed MRAS-NF-SMC controller provides a good dynamic behaviour, and an excellent tracking of the requested trajectory
\end{abstract}

Keywords- Neuro Fuzzy, wind turbine, DFIG, SMC, MRAS.

\section{INTRODUCTION}

Nowadays, fossil fuel-based energy sources are the most widespread in the world. The energy consumption has increased significantly. The use of new sources of energy becomes necessary. Technological development has made it possible to explore new sources of energy that are renewable and can be used with affordable costs. The use of renewable energies becomes of great importance because of their benefits. Wind energy is an interesting source for renewable energy. It is a subject of recent researches and industrial applications. The control of wind energy conversion system (WECS) using a doubly fed induction generator (DFIG) is more complex, therefore, it needs effective strategy of control [1-2].

In this work, a MRAS technique is used, including two nonlinear approaches: Neuro-fuzzy (NF) theory and sliding mode (SM) technique. The NF networks is very interesting because it exploits the merits for both neural network and fuzzy logic techniques, the Neuronal structure is used to improve the structure of fuzzy inference system(FIS) $[3,4]$.

The organisation of this work is as follows: the power control systemis described in the second section. In the third section, the model of DFIG is presented and the strategy of vector control is considered in the power control. In the fourth section, a Neurofuzzy controller is developed in order to control the active and reactive power of DFIG. The fifth section is devoted to develop an adaptive mechanis mbased on SMC method. Simulation results are given to show the effectiveness of this controller and finally conclusions are summarized in the last section.

\section{DESCRIPTION OF THE SYSTEM}

The schematic diagram of the power control system under study is shown in Fig. 1. The wind power is transformed to electrical energy via wind turbine using a DFIG. The power generated by the DFIGis controlled by the rotor voltages and then by the inverter [5-7].

An improved MRAS method is proposed to control the DFIG generated power. This technique is composed of the reference model, NF controller and an adaptive mechanism based on SMC. The proposed controller MRAS based on NF and SMC (MRAC-NF-SMC) is given in Fig. 2., where $Y$ is the controlled variable (it can present $P_{s}$ or $Q_{s}$ ). The reference model (RF) represents the desired dynamic of the system with nominal parameters. [8].

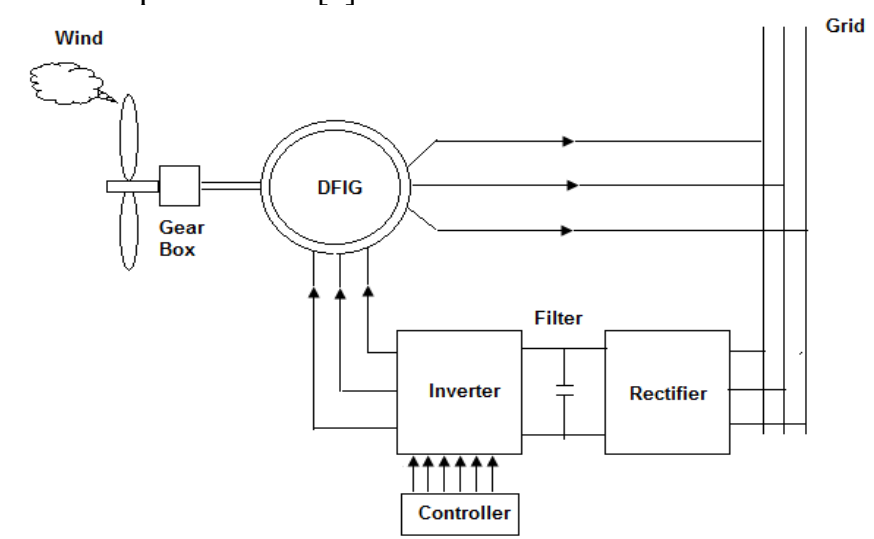

Fig. 1. Configuration of DFIG-wind turbine.

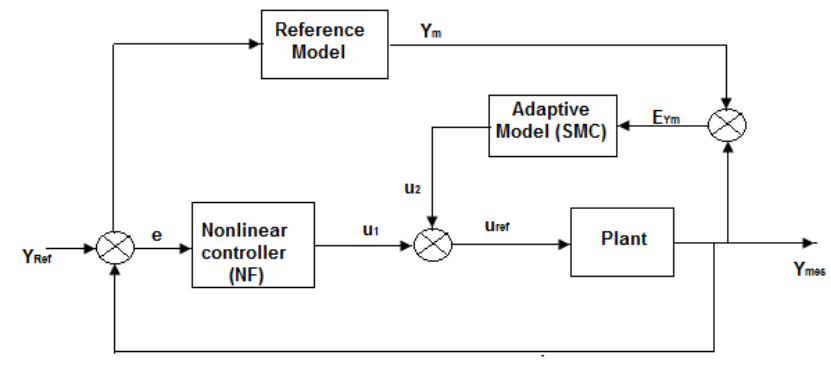

Fig. 2. The structure of the MRAC-NF-SMC.

\section{MODELING OF THE DFIG}

The simplified model of DFIG in park frame is described by the following equations: 


$$
\left\{\begin{array}{l}
v_{d r}=R_{r} i_{d r}+\ell_{r} \sigma \frac{d i_{d r}}{d t}-g \omega_{s} \ell_{r} \sigma i_{q r} \\
v_{q r}=R_{r} i_{q r}+\ell_{r} \sigma \frac{d i_{q r}}{d t}+g \omega_{s} \ell_{r} \sigma i_{d r}+g \frac{L_{m} v_{s}}{\ell_{s}}, \\
g=\frac{\omega_{s}-\omega_{r}}{\omega_{s}}
\end{array}\right.
$$

Fig. 3 describes the simplified DFIG model. In where, $v_{q r}$ and $v_{d r}$ are the inputs as the $P_{s}$ and $Q_{s}$ are the outputs of this block diagram.

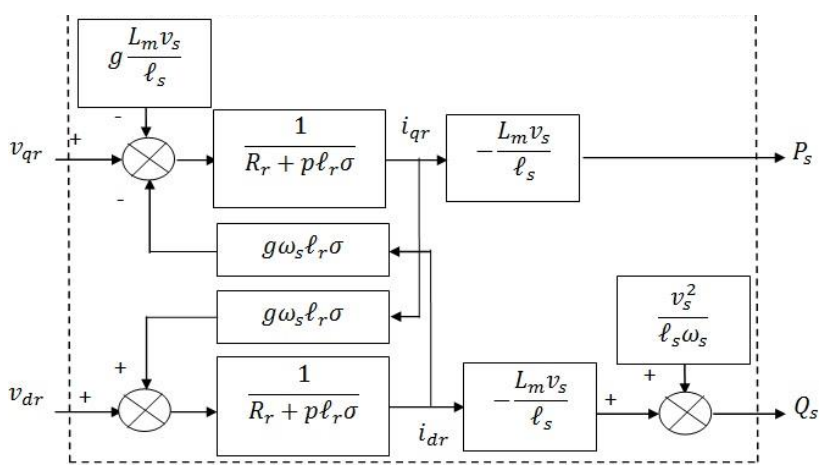

Fig. 3. Block diagram of simplified DFIG model.

In this work, we use the stator field orientation control strategy as described in references [6-7]. The active and reactive power can be controlled separately following the direct and quadrature components of the rotor current as given in Eq. (2).

$\left\{\begin{array}{l}P_{s}=-v_{s} \frac{L_{m}}{\ell_{s}} i_{q r} \\ Q_{s}=-v_{s} \frac{L_{m}}{\ell_{s}} i_{d r}+\frac{v_{s}^{2}}{\ell_{s} \omega_{s}}\end{array}\right.$

We can decouple the rotor voltage equations by introducing the compensation terms as in Eq. (3):

$\left\{\begin{array}{l}F_{e m d}=g \omega_{s} \ell_{r} \sigma i_{q r} \\ F_{e m q}=g \omega_{s} \ell_{r} \sigma i_{d r}+g \omega_{s} \frac{L_{m} v_{s}}{\omega_{s} \ell_{s}}\end{array}\right.$

\section{ADAPTIVE NEURO-FUZZY MODE POWER CONTROLLER}

\section{A. Adaptive Neuro-Fuzzy Principle}

A typical architecture of an ANFIS is shown in Fig. 4. In which a circle indicates a fixed node, whereas a square indicates an adaptive node. For the simplicity, we consider two inputs $x, y$ and one output $z$ [9].

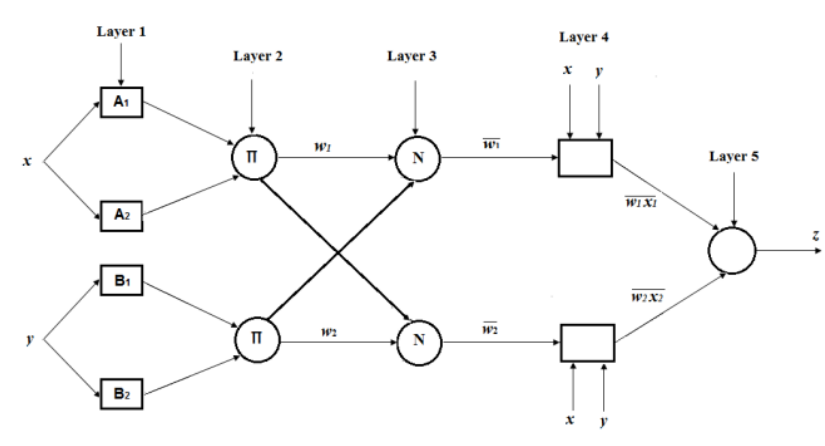

Fig. 4. Architecture of ANFIS [9].

Among many FIS models, the Sugeno fuzzy model is the most widely used. For a first order Sugeno fuzzy model, a common rule set with two fuzzy if-then rules can be expressed as:

Rule: If $x$ is $A_{1}$ and $y$ is $B_{1}$, Then $z_{1}=p_{1} x+q_{1} y+r_{1}$ Rule: If $x$ is $A_{2}$ and $y$ is $B_{2}$, Then $z_{2}=p_{2} x+q_{2} y+r_{2}$

Where $A_{\mathrm{i}}$ and $B_{\mathrm{i}}$ are the fuzzy sets in the antecedent, and $p_{\mathrm{i}}$ $q_{\mathrm{i}}$ and $r_{\mathrm{i}}$ are the design parameters that are determined during the training process.

The ANFIS of fig. 4 consists of five layers:

- Layer 1: Every node $i$ in the first layer employs a node function given by Eq. (4):

$$
\begin{array}{ll}
O_{i}^{1}=\mu_{A_{i}}(x), & i=1,2 \\
O_{i}^{1}=\mu_{B_{i}}(y), & i=3,4
\end{array}
$$

Where $\mu_{A_{i}}$ and $\mu_{B_{i}}$ can adopt any fuzzy membership functions (MF).

- Layer 2: Every node in this layer calculates the firing strength of a rule via multiplication as in Eq. (5).

$$
O_{i}^{2}=w_{i}=\mu_{A_{i}}(x) \mu_{B_{i}}(y), \quad i=1,2
$$

- Layer 3: The $i^{\text {th }}$ node in this layer calculates the ratio of the $i^{\text {th }}$ rule's firing strength to the sum of all rules firing strengths as in Eq. (6):

$$
O_{i}^{3}=\overline{w_{i}}=\frac{w_{i}}{w_{1}+w_{2}}, \quad i=1,2
$$

Where $w_{i}$ is referred to as the normalized firing strengths.

- Layer 4: In this layer, every node $i$ has the following function As in Eq. (7):

$$
O_{i}^{4}=\overline{w_{i}} z_{i}=\overline{w_{i}}\left(p_{i} x+q_{i} y+r_{i}\right), \quad i=1,2
$$

Where $\overline{w_{i}}$ is the output of layer 3 , and $\left\{p_{i}, q_{i}, r_{i}\right\}$ is the parameterset. The parameters in this layer are referred to as the consequent parameters. 
- Layer 5: The single node in this layer computes the overall output as the summation of all incoming signals, which is expressed as given in Eq. (8):

$$
O_{i}^{5}=\sum_{i=1}^{2} \overline{w_{i}} z_{i}=\frac{w_{1} z_{1}+w_{2} z_{2}}{w_{1}+w_{2}}
$$
11]:

The output $z$ in Fig. 2 can be rewritten as in Eq. (9) [10,

$$
z=\left(\overline{w_{1}} x\right) p_{1}+\left(\overline{w_{1}} y\right) q_{1}+\left(\overline{w_{1}}\right) r_{1}+\left(\overline{w_{2}} x\right) p_{2}+\left(\overline{w_{2}} y\right) q_{2}+\left(\overline{w_{2}}\right) r_{2}
$$

\section{B. Adaptive Neuro-Fuzzy Controller \\ B.1. Active power controller:}

The adaptive neural fuzzy inference system (ANFIS) is based on fuzzy logic controller with rules and inferences issued from a learning method. This last will train the parameters of the membership functions of the fuzzy logic controller and learn it more about the information of the inputs data as described in references $[9,10]$.

For that, we developed the ANFIS as:

- First order Sugeno Type

- The error and change of error as inputs

- The control action as output

- Bell membership functions

- Hybrid optimization method

- Number of iterations 30

- Error tolerance $10^{-5}$

The Fig. 5 describes the ANFIS structure.

The ANFIS controller generates change in the reference voltage based on active power error $\left(e_{p}\right)$ defined as in Eq. (10):

$$
e_{P}=P_{r e f}-P_{s}
$$

Where $P_{r e f}$ and $P_{s}$ are the reference and the actual active power, respectively.

The number of epochs was 30 for training. The number of MFs for the inputs (e) and (de) are 5, after training we can obtain the MFs of the inputs the forms are shown in in Figs. 6 and 7. The Bell MF is used for the input variable. Fig. 8 highlights surface of the ANFIS using the input and the output.

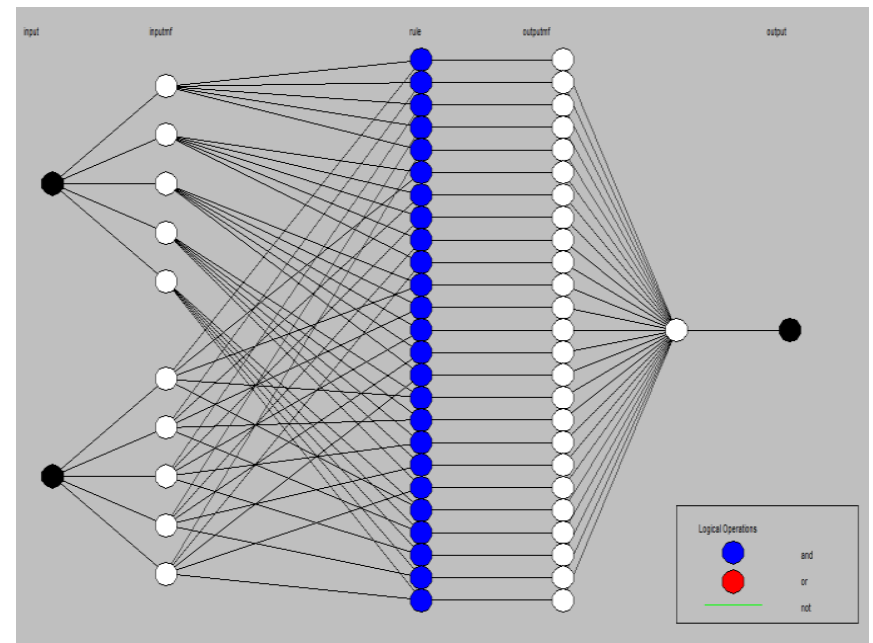

Fig. 5. The ANFIS structure

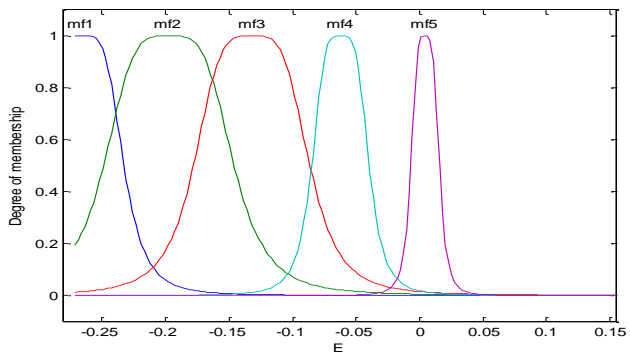

Fig. 6. Membership functions for $e$.

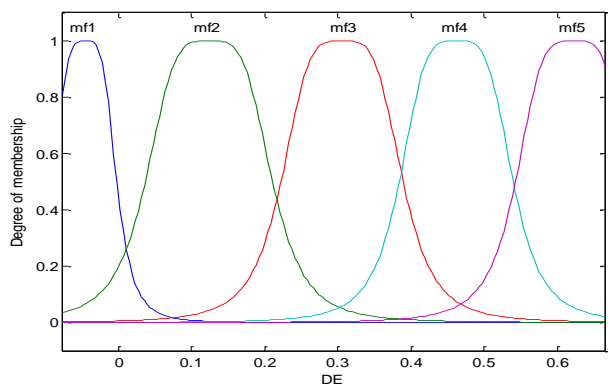

Fig. 7. Membership functions for $D E$.

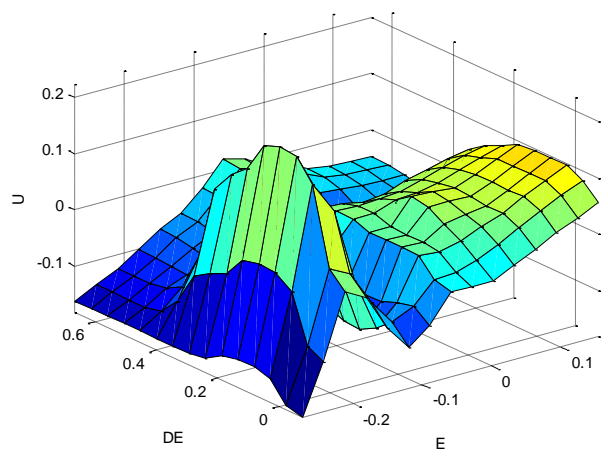

Fig. 8. The output surface of the ANFIS using the inputs and the output. 


\section{B.2. Reactive power controller:}

The adaptive neural fuzzy inference system (ANFIS) is based on fuzzy logic controller with rules and inferences issued from a learning method. This last will train the parameters of the membership functions of the fuzzy logic controller and learn it more about the information of the inputs data as given in references $[9,10]$.

The ANFIS is:

- First order Sugeno Type

- The error and change of error as inputs

- The control action as output

- Bell membership functions

- Hybrid optimization method

- Number of iterations 100

- Error tolerance $10^{-4}$

The Fig. 5 shows the structure of proposed ANFIS is structured and the surface view between inputs and outputs. The number of epochs for training was 100 . The number of MFs for the inputs (e) and (de) are 5, after training we can obtain the MFs of the inputs the forms are presented in Figs. 9 and 10. The Bell MF is used for the input variable. Fig. 11 depicts surface of the ANFIS using the input and the output.

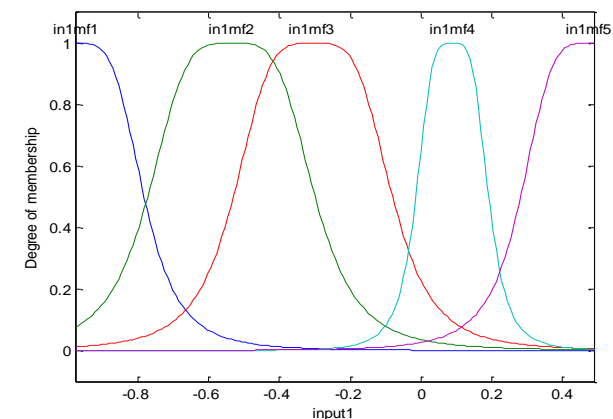

Fig. 9. Membership functions for $e$.

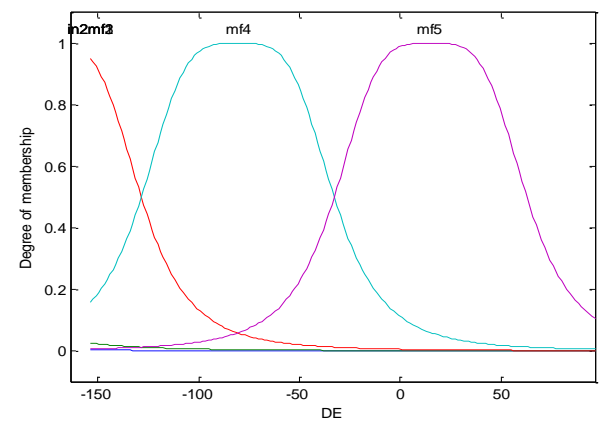

Fig. 10. Membership functions for De.

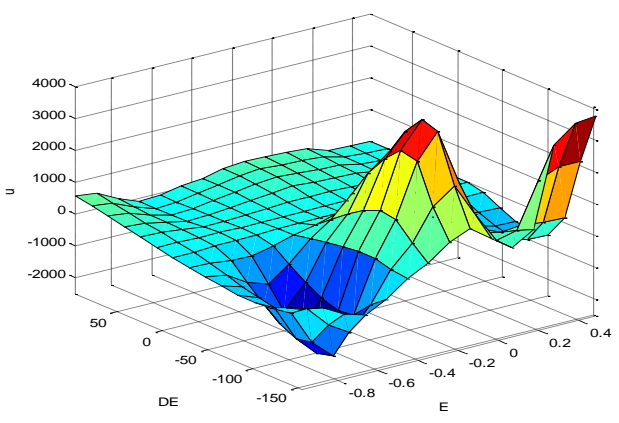

Fig. 11. The output surface of the ANFIS us ing the inputs and the output.

\section{ADAPTIVE MECHANISM}

\section{A. Control of The Active Power}

We choose the surface of the commutation of the sliding mode controller in the following formas given in Eq. (10) [10, 11]:

$$
S\left(P_{S}\right)=P_{S}^{r e f}-P_{S}
$$

From (11), we can obtain the derivative of the surface as in given in Eq. (12):

$$
\dot{S}\left(P_{S}\right)=\dot{P}_{S}^{r e f}-\dot{P}_{s},
$$

By substituting $P_{s}$ by its expression and considering $v_{q s}$ equal to $v_{s}$, we obtain Eq. (13):

$$
\dot{S}\left(P_{s}\right)=\dot{P}_{s}^{r e f}+\frac{m_{s r} v_{s}}{l_{s}} \dot{i}_{q r}
$$

We extract the expression of $i_{q r}$ from (1) and replace it in (13), we obtain Eq. (14):

$$
\dot{S}\left(P_{s}\right)=\dot{P}_{s}^{r e f}+\frac{m_{s r} v_{s}}{l_{s} l_{r} \sigma}\left(v_{q r}-r_{r} i_{q r}-g \omega_{s} l_{r} \sigma i_{d r}-g \frac{m_{s r} \phi_{s}}{l_{s}}\right),
$$

In steady state, we can define the stator flux by Eq. (15):

$$
\varphi_{s}=\frac{v_{S}}{\omega_{s}}
$$

The control of the active power is described by Eq. (16):

$$
v_{q r}=v_{q r}^{e q}+v_{q r}^{n}
$$

In sliding surface, we have: $S\left(P_{s}\right)=0, \dot{S}\left(P_{s}\right)=0$, Using expression in Eq. (14), neglecting g, we can obtain $v_{q r}^{e q}$ as given in Eq. (17) 


$$
v_{q r}^{e q}=\frac{-l_{s} l_{r} \sigma}{m_{s r} v_{s}} \dot{P}_{s}^{r e f}+r_{r} i_{q r},
$$

The expression of $v_{q r}^{n}$ as given in Eq. (18):

$$
v_{q r}^{n}=k_{v q r} \operatorname{sign}(P),
$$

Where $k_{v q r}$-is a positive constant.

\section{B. Control of the Reactive Power}

The surface commutation of the reactive power is defined by Eq. (19) $[10,11]::$

$$
S\left(Q_{s}\right)=Q_{s}^{r e f}-Q_{s},
$$

And by derivation, we obtain Eq. (20):

$$
\dot{S}\left(Q_{s}\right)=\dot{Q}_{s}{ }^{r e f}-\dot{Q}_{s},
$$

By substituting $Q_{s}$ by its expression from in Eq. (2) and replacing the stator flux $\varphi_{s}$ we obtain Eq. (21):

$$
\dot{S}\left(Q_{s}\right)=\dot{Q}_{s}^{r e f}+\frac{m_{s r} v_{s}}{l_{s}} \dot{i}_{d r},
$$

By extracting the $\dot{i}_{d r}$ from in Eq. (1) and substituting it in Eq. (21) we obtain Eq. (22):

$$
\dot{S}\left(Q_{s}\right)=\dot{Q}_{s}^{r e f}+\frac{m_{s r} v_{s}}{l_{s} l_{r} \sigma}\left(v_{d r}-r_{r} i_{d r}+g \omega_{s} l_{r} \sigma i_{q r}\right),
$$

The control of the reactive power is calculated as given in Eq. (23):

$$
v_{d r}=v_{d r}^{e q}+v_{d r}^{n}
$$

In sliding surface $S\left(Q_{s}\right)=0, \dot{S}\left(Q_{s}\right)=0$, neglecting g, we obtain the expression of $v_{d r}^{e q}$ as described in Eq. (24):

$$
v_{d r}^{e q}=\frac{-l_{s} l_{r} \sigma}{m_{s r} v_{s}} \dot{Q}_{s}^{r e f}+r_{r} i_{d r},
$$

The expression of $v_{d r}^{n}$ is given as in Eq. (25):

$$
v_{d r}^{n}=k_{v d r} \operatorname{sign}(P)
$$

Where $k_{v d r}-$ is a positive constant.

\section{SIMULATION RESULTS}

In order to validate the controlstrategies as discussed above, digital simulation studies of the system described in Figs. 1 and 2 were done. The simulation is realized using the SIMULINK software in MATLAB environment.

Fig. 12 depicts the performances of the response of the system controlled by MRAS_NF-SMC controller. An increase of the wind speed is accompanied by an increase in active power generated by the wind turbine and then the increase of the quadrature rotor current $i_{q r}$. A decoupled control of the active and reactive powers is realised using vector control; the active power can be controlled separately by the direct rotor current, and the reactive control by the quadrature rotor current.

Figs. 13 and 14 show respectively the control of the active and the reactive power delivered by the DFIG. The results show the high performance of the control technique used in tracking the desired trajectory with negligible error in permanent mode. The active power and the reactive power generated track well the desired value given by the reference models.

Figs 15 and 16 introduce the test of robustness considering the case of unknown or a wrong value of the rotor resistance. The results show that control of active and reactive power with the proposed controller retains its best qualities of control despite disturbances. 

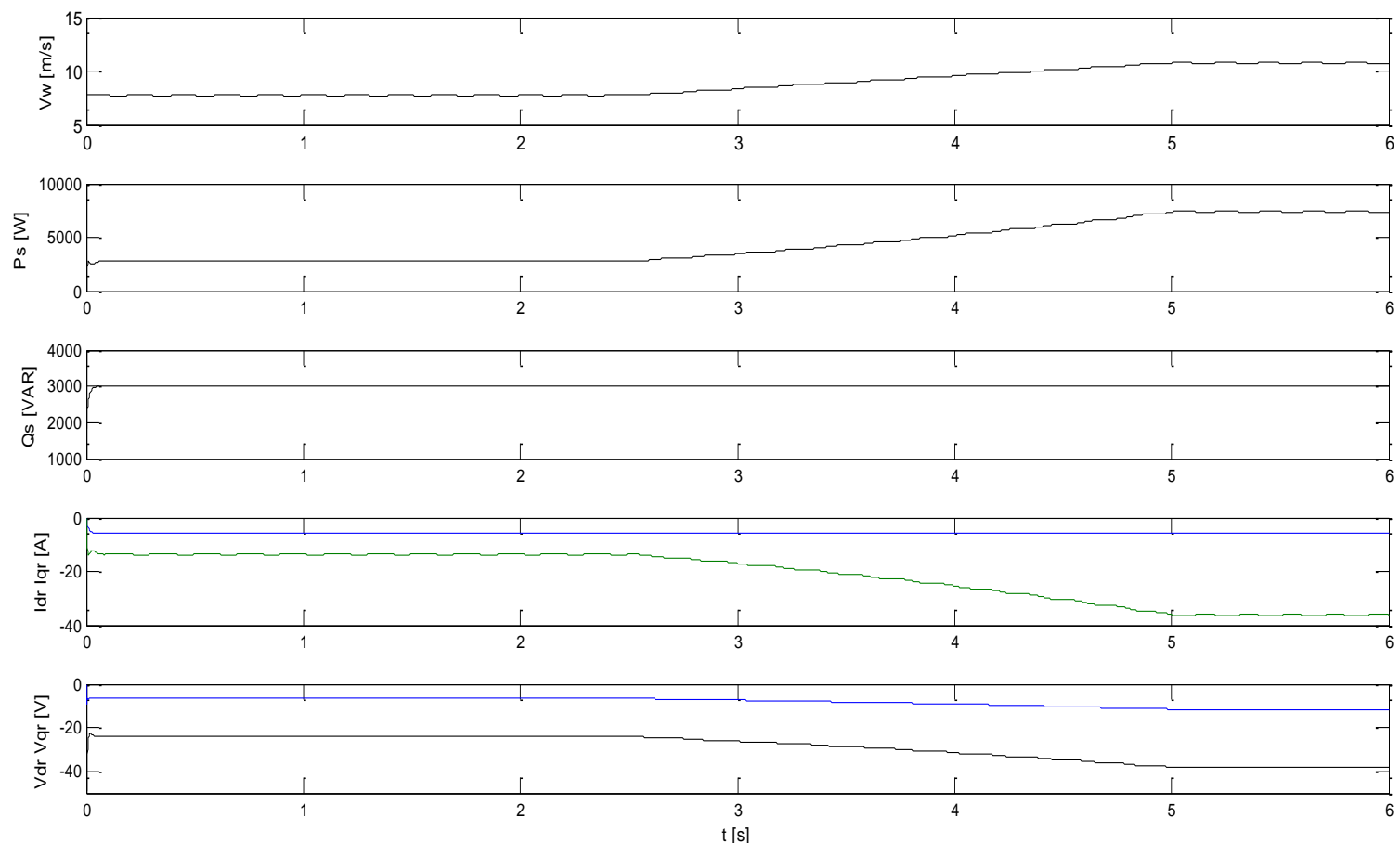

Fig. 12 The response of the system controlled by MRAS_NF-SMC controller

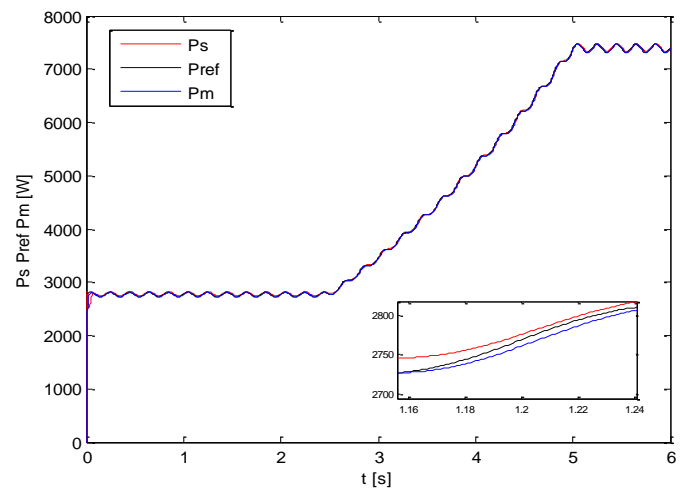

Fig. 13. The active power control using MRAS_NF-SMC controller

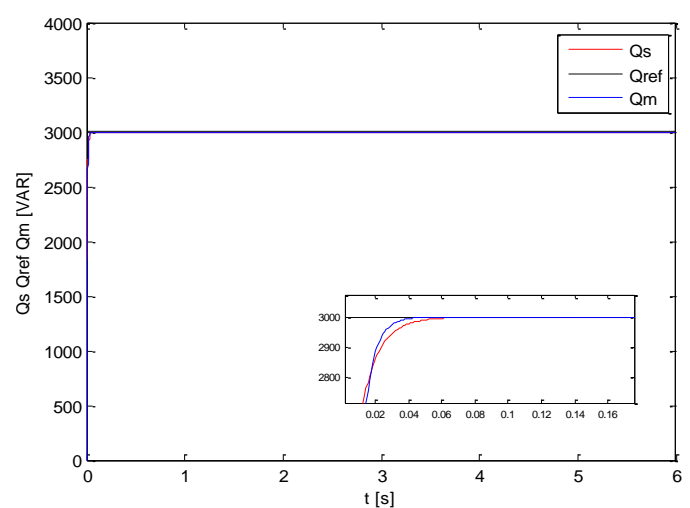




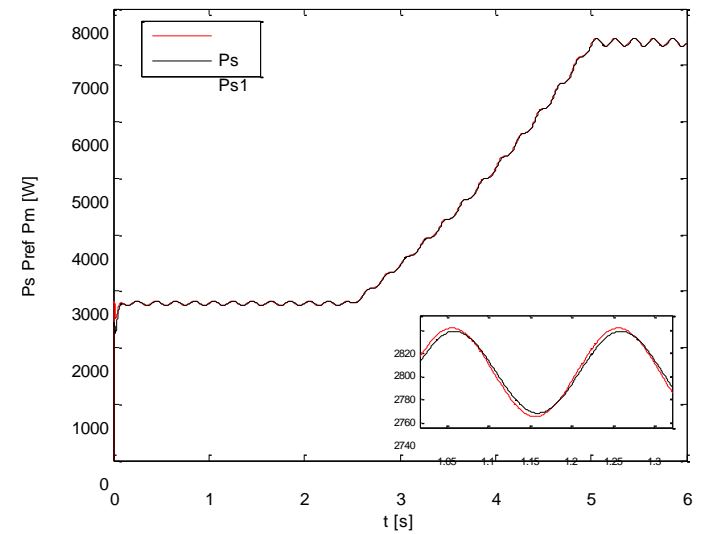

Fig. 16. The test of robustness using the proposed active power controller: Ps (Rs), Qs1 (1.5Rs)

\section{CONCLUSION}

The control of the power generated by the wind turbine is important. In this paper we presented a technique of the controlbased on MRAS system. The structure of the MRAS was developed using the Anfis methodology in the direct control and the SMC in the adaptive mechanism. First the model of the DFIG was given. Then, the structure of the controller was presented and applied to the control of the active and reactive power generated by the wind turbine. The performances of the proposed controller MRAC-F-SMC gave best responses.

The MRAS-NF-SMC has a good behavior in dynamic performance and ability to reduce the effect of the internal and external disturbances on the system; it can be considered a robust technique of control. The implementation of this controller can be the subject of future studies.

\section{Appendix}

Rated data of the simulated doubly fed induction generator: $7.5 \mathrm{~kW}, \quad v_{s}=220 \mathrm{~V}, \quad F_{s}=50 \mathrm{~Hz}, \quad p=3, \quad J=0.1 \mathrm{~kg} / \mathrm{m}^{2}$, $f=0.06 \mathrm{~N} . \mathrm{m} . \mathrm{s} / \mathrm{rad}, \quad R_{s}=0.95 \Omega \quad R_{r}=1.8 \Omega, \quad L_{m}=0.082 \mathrm{H}, \quad \ell_{s}$ $=0.094 \mathrm{H}, \ell_{r}=0.088 \mathrm{H}$.

Wind turbine parameters: $P_{m}=10 \mathrm{kw}$, number of blades $=3$, $R=3.5 \mathrm{~m}, G=5.4, J=0.042 \mathrm{~kg} . \mathrm{m}^{2}, f=0.017 \mathrm{~N} . \mathrm{m} . \mathrm{s} / \mathrm{rad}$.

\section{REFERENCES}

[1]. S. El Aimani, "Modeling of Different Integrated Wind Turbine Technologies in a Medium Voltage Network", Phd thesis in Electrical Engineering, University of Science and Technology of Lille, France, 2004

[2]. F. Poitiers, "Study and control of asynchronous generators for the use of wind energy, asynchronous machine with autonomous cage, asynchronous machine with dual power supply connected to the network", Phd thesis in Electrical Engineering, University of Nantes, 2003.

[3]. Brown, M. and Haris, C., (1994) Neuro-fuzzy adaptive modeling and control, Englewood Cliffs, Prentice-Hall.

[4]. Constantin, V.A., (1995) Fuzzy logic and neuro-fuzzy applications explained, Englewood Cliffs, Prentice-Hall.

[5]. A. G. Aissaoui, A.T ahour, M.Abid, N. Essounbouli, F.Nollet, M. Chergui, "Variable Structure Control Applied in Wind Turbine
Based on Induction Generator", International Journal of Renewable Energy Research (IJRER), Vol. 2, No 4, 2012, pp. 600-6007

[6]. A.G. Aissaoui, A. Tahour, M. Abid, N. Essounbouli, F. Nollet, "A Fuzzy-PI control technique designed for Power Control of Wind Turbine based on Induction Generator", Advanced Materials Research Vols. 875-877 (2014) pp 16761682. (C) (2014) Trans Tech Publications, Switzerland, doi:10.4028/www.scientific.net/AMR.875-877.1676

[7]. A.G. Aissaoui, A. Tahour, M. Abid, N. Essounbouli, F. Nollet, "Power Control of Wind Turbine based on Fuzzy Controllers", Journal of energy procedia, Mediterranean Green Energy Forum 2013: Proceedings of an International Conference MGEF-13, Volume 42, 2013, Pages 163-172. Edited by Robert J. Howlett, Nacer Kouider M'Sirdi, Aziz Naamane and Ali Sayigh.

[8]. Abdel Ghani Assaoui, Mohamed Abid, Hamza ABID and Ahmed Tahour, «Reference model adaptive control of sychronous machine», Revue Roumaine des Sciences Techniques Série Electrotechnique et Energétique, ISSN 00354066, Vol 53; Part 3, 2008, page(s) 241-251.

[9]. A.G. AissaOUI, M. ABID, A. TAHOUR, A.C. MEGHERBI, "Synchronous motor speed control based on ANFIS methodology and sliding mode observer", International Journal of Artificial Intelligence and Soft Computing, Vol. 5, No. 1, 2015, pp. 3-22.

[10]. M. Doumi, A. G. Aissaoui, M. Abid, I. Colak, A. Tahour, "Robust MRAC For A Wind Turbine Based On A Doubly-Fed Induction Generator", 6th International Conference on Renewable Energy Research and Applications (ICRERA), San Diego, CA, USA, 5-8 November, 2017.

\section{Creative Commons Attribution License 4.0 (Attribution 4.0 International, CC BY 4.0)}

This article is published under the terms of the Creative Commons Attribution License 4.0 https://creativecommons.org/licenses/by/4.0/deed.en_US 